\title{
Erratum: Nucleus Accumbens, a new sleep-regulating area through the integration of motivational stimuli
}

Sara VALENCIA GARCIA, Patrice FORT

Acta Pharmacologica Sinica (2018), doi:10.1038/aps.2017.168, published online 28 December 2017.

After publication of the article, it has been brought to our attenetion that there is a discrepancy between the publication date on the pdf and online formats. The date on the pdf is 28 December 2017 and online is 28 December 2018. The correct publication date is the one on the pdf, 28 December 2017.

Acta Pharmacologica Sinica (2018) 39: 1064; doi: 10.1038/aps.2018.41 